\title{
CDISC SDTM Method Terminology
}

National Cancer Institute

\section{Source}

National Cancer Institute. CDISC SDTM Method Terminology. NCI Thesaurus. Code C85492.

Terminology associated with the method codelist of the Clinical Data Interchange Standards Consortium (CDISC) Study Data Tabulation Model (SDT M). 